\title{
A centralidade das políticas sociais no capitalismo: uma análise da Era Thatcher
}

André Simões'

\section{Resumo}

O presente artigo tem como objetivo mostrar a inviabilidade do projeto neoliberal de construção de uma economia baseada nas forças de mercado, ressaltando, ao mesmo tempo, a importância das políticas sociais para o processo de reprodução do capitalismo. A partir da análise da experiência britânica no período marcado pelo governo da Primeira Ministra Margareth Thatcher, pretende-se mostrar como a tentativa de criação de uma economia de mercado produziu um contramovimento de proteção da sociedade. Este último pode ser notado tanto no aumento dos gastos sociais quanto no processo de reestruturação das políticas sociais.

Palavras-chave: Crise econômica. Neoliberalismo. Políticas sociais. Gastos sociais.

\section{Introdução}

Desde a publicação, em 1776, do livro "A Riqueza das Naçôes" de Adam Smith, estudiosos se dedicam a desenvolver teorias explicativas sobre o funcionamento do capitalismo. Essa motivaçáo esteve na origem do surgimento de uma série de correntes de pensamento ao longo de todo o século XX, que forneceram as bases para a formulação de políticas voltadas para o desenvolvimento dos países.

Embora pertencentes a diferentes matrizes teóricas, essas correntes de pensamento possuem um ponto em comum: encontram-se fundamentadas na problemática que envolve as relaçôes entre Estados e mercado. A teoria neoclássica, por exemplo, confere primazia ao mercado no funcionamento do

I Pesquisador do Instituto Brasileiro de Geografia e Estatística (IBGE). Doutor em Economia da Indústria e da Tecnologia pela Universidade Federal do Rio de Janeiro e Mestre em Planejamento Urbano e Regional pela mesma Universidade.E-mail: andresimoes36@gmail.com.0 IBGE não se responsabiliza por opiniões, informações, dados e conceitos contidos neste artigo, que são de exclusiva responsabilidade do autor. 
capitalismo, abrindo espaço para a intervenção estatal no sistema econômico apenas quando este apresentar falhas que comprometam sua eficiência. Já a teoria keynesiana minimiza a eficácia de uma economia conduzida unicamente pelas forças de mercado, mostrando que o Estado é a instituição fundamental para garantir a elevação do nível de produção acima daquele fixado pelo mercado.

A abordagem da Economia Política Institucional ${ }^{2}$, por sua vez, insere a referida relação em uma problemática que remete às condiçóes de reprodução do capitalismo. Assim como a interpretação marxista, os institucionalistas atribuem ao capitalismo contradiçóes que impedem que o processo de acumulação seja conduzido exclusivamente pelas forças de mercado (POLANYI, 2000; GOUGH, 1979). Nesse sentido, a natureza fictícia da força de trabalho particulariza o seu processo de (re)produção, diferenciando-o das demais mercadorias. A necessidade de condições básicas de reprodução da força de trabalho se encontra além da garantia de um salário de subsistência, incluindo, da mesma forma, o acesso à moradia, ao saneamento, à saúde e à educação. $\mathrm{O}$ mercado, dessa forma, mostra-se insuficiente em prover os meios que garantam essa reprodução, o que abre espaço para a atuação de instituiçóes não mercantis, como o Estado.

Nesta abordagem, o Estado assume um papel mais amplo no capitalismo, ao garantir as condiçóes para que a expansão dos mercados ocorra sem que haja o rompimento dos seus vínculos com as instituiçóes políticas e sociais do sistema. Os mercados perdem sua primazia, assumindo a condição de mais uma instituição - de fato importante - que se desenvolveu ao longo da história. Em outras palavras, para os adeptos da Economia Política Institucional, o mercado se expande a partir da atuação do Estado, estando, por isso, enraizado nas instituições políticas e sociais das sociedades capitalistas, que condicionam o seu desenvolvimento.

Imbuído desta visão, Polanyi (2000) mostra, a partir de evidências históricas, que a inversão dessa lógica - tentativas de submissão das instituiçóes políticas e sociais à lógica de funcionamento do mercado -, produziu o aumento da vulnerabilidade social da população. Para o referido autor, a total

2 Denominou-se de "Economia Política Institucional" a corrente analítica inaugurada por Karl Polanyi, que vincula o funcionamento do sistema capitalista ao movimento de suas instituições. 
mercantilização da vida social, viabilizada pela criação de um padrão institucional chamado "sistema de mercado", é incompatível com o processo de reprodução da força de trabalho. Nessas situaçóes, como na Revolução Industrial Inglesa, a proteção social acabou se fazendo presente, mediante a promulgação de uma série de legislaçóes, inviabilizando a total desregulamentação dos mercados.

O capitalismo, dessa forma, não teria condiçóes de se reproduzir exclusivamente por meio das relaçóes estabelecidas pelo mercado. A necessidade de atuação de instituiçóes extramercantis, como o Estado, conferem, portanto, centralidade às políticas sociais no capitalismo. Seja atuando de forma mais restrita, como na correção das falhas de mercado ou de forma mais ampla, pela manutenção dos níveis de coesão social, as políticas sociais desempenharam papel importante no capitalismo contemporâneo, principalmente no período que se seguiu ao término da $2^{\text {a }}$ Guerra Mundial.

O presente artigo se desenvolve no âmbito dessa temática. Partindo das críticas à visão neoliberal sobre a primazia do mercado no capitalismo, objetiva mostrar como as políticas sociais, enquanto vetores de atuação do Estado se revelam instituiçóes centrais no processo de acumulaçáo de capital. Nesse sentido, a análise da experiência britânica ao longo dos governos dos Primeiros Ministros Margareth Thatcher e John Major - período aqui chamado de Era Thatcher (1979-1997) - fornece importante evidência das contradiçóes geradas pela tentativa de estabelecimento de uma economia de mercado.

A hipótese defendida ao longo do trabalho é de que o processo de desregulamentação econômica impingido pelo referido governo produziu o aumento da vulnerabilidade social da população, inviabilizando, dessa forma, a estratégia conservadora de redução da atuaçáo social do Estado. Em outras palavras, propóe-se mostrar que a tentativa de criação de um sistema altamente desregulamentado produziu um contramovimento de proteçáo da sociedade, evidenciado na manutenção de um amplo sistema de proteção social - ainda que o mesmo tenha sido reestruturado e adquirido feiçóes neoliberais ${ }^{3}$.

3 Em um trabalho por meio do qual busca criticar a fundamentação teórica da economia política neoliberal, Chang (2003) mostra que sua formação ocorreu através de uma "aliança espúria" entre a tradição econômica neoclássica e a tradição libertária austríaca. Essa aliança é espúria porque une duas tendências contrárias, isto é, a econômica neoclássica - que abre espaço para uma ampla intervenção estatal, a partir do conceito de falhas de mercado - e a tradição libertária austríaca - que atua no plano político e possui um discurso 
O artigo está dividido em três partes. Na primeira delas, serão analisadas as transformaçóes estruturais na economia britânica durante a década de 1980, procurando mostrar como as limitaçóes do modelo de desenvolvimento do Pós-II Guerra Mundial que objetivava combater a crise econômica dos anos 1970 abriu caminho para a introdução de um novo paradigma de política econômica, responsável pelo processo de reestruturação da economia da Inglaterra. É igualmente objeto de análise a discussão das relaçóes estabelecidas entre as políticas econômicas de orientaçáo neoliberal e o comportamento dos gastos governamentais e dos sociais, em particular.

A segunda parte deste artigo se ocupa em analisar mais profundidade como as transformaçóes no paradigma de política econômica implementadas pelo governo Thatcher (1979-1990) mudaram profundamente as relaçóes entre política econômica e social no Reino Unido. Em linhas gerais, pode-se adiantar que, devido à real impossibilidade de desmantelamento das políticas sociais, o governo passou a reestruturá-las, condicionando o seu funcionamento, em grande medida, à lógica das políticas econômicas neoclássicas.

Por fim, a terceira parte deste estudo discute as questóes analisadas nas seçóes anteriores a partir do estudo do processo de reestruturaçáo das políticas de manutenção da renda ao longo da década de 1980.

\section{As transformações estruturais no capitalismo e seus efeitos sobre as políticas sociais}

O período que se inicia com a chegada ao poder da Primeira Ministra Margaret Thatcher pode ser tomado como resultado de uma série de acontecimentos ocorridos tanto no plano econômico como político que criaram as condiçóes favoráveis para o avanço do pensamento neoliberal. No plano econômico, destacam-se duas crises que, em conjunto, minaram a efetividade das políticas econômicas do período Pós-II Guerra Mundial.

Em primeiro lugar, estão os efeitos que as duas Crises do Petróleo (1973 e 1979) tiveram sobre a elevação do preço dessa matéria-prima no mercado

altamente liberal. Pode-se afirmar que a internalização dos valores libertários pela academia e a politização da economia neoclássica geraram uma aliança que limitou a abrangência do potencial intervencionista da economia neoclássica a uma fronteira aceitável para o avanço da agenda neoliberal. Em outras palauras, houve uma captura da economia neoclássica pelos seguidores do neoliberalismo. 
internacional, com efeitos expansivos não apenas sobre a inflação doméstica mas também sobre os custos de produção das empresas. A redução do ritmo de crescimento da produçáo nos países centrais aumentou as taxas de desemprego, mesmo em um contexto de crescimento da inflação, fenômeno que ficou conhecido como stagflação.

Em segundo lugar, encontra-se a crise no padrão monetário internacional, iniciada pelo movimento dos Estados Unidos voltados a romper os pilares básicos que regiam a política monetária internacional, a qual foi instituída pelo acordo de Bretton Woods (BAER et al., 1994). A crise no Balanço de Pagamentos norte-americano forçou o governo a suspender tanto a conversibilidade do dólar frente ao ouro - como forma de evitar a fuga de dólares para os demais países - quanto a promover uma desvalorizaçáo cambial à revelia dos demais países. Este processo forçou especialmente os países europeus a executarem políticas monetárias defensivas, como forma de se protegerem dos efeitos das políticas macroeconômicas norte-americanas. De acordo com Tavares (1993), as políticas adotadas por esses países, previam, a um só tempo, combater a inflação e equilibrar o balanço de pagamentos, o que seria feito mediante sucessivas desvalorizaçóes nas taxas de câmbio. E isso, por um lado, aumentaria a competitividade dos produtos europeus no mercado internacional - estimulando a produçáo doméstica -; por outro lado, equilibraria o balanço de pagamentos com o superávit da balança comercial. Ancoradas nos pressupostos das políticas econômicas do Pós-II Guerra Mundial, no entanto, essas políticas náo previam os efeitos das expectativas de flutuação cambial sobre o movimento de capitais de curto prazo, o que passou a comprometer a conta de capitais do Balanço de Pagamentos, anulando os ganhos oriundos do superávit comercial. Cabe ressaltar, além disso, que as referidas políticas não previam que as desvalorizaçóes cambiais aumentassem os efeitos inflacionários causados pelas crises do petróleo, o que entrava em contradição com as políticas direcionadas à estabilização dos salários e dos preços (TAVARES, 1993).

Em outras palavras, observa-se uma ineficiência das políticas econômicas do Pós-II Guerra Mundial em combater a crise que se abateu sobre as economias centrais. Nesse sentido, mudanças no campo político ocorreram como uma resposta às transformaçóes no campo econômico, na medida em que as coalizóes políticas formadas no Pós-Guerra não estavam conseguindo enfrentar a crise econômica com a utilização dos instrumentos clássicos de 
política econômica vinculados à tradição keynesiana da síntese neoclássica ${ }^{4}$, abrindo caminho para a ascensáo ao poder de coalizóes políticas defensoras das políticas econômicas ortodoxas como fundamentais para a estabilização das economias nacionais.

É dentro desse contexto que se podem situar as profundas mudanças implementadas na economia britânica, as quais repercutiram as transformaçóes na natureza das políticas econômicas. Para Hall (1990), os processos que minaram a efetividade das políticas econômicas vinculadas à síntese neoclássica no combate à crise dos anos 1970 pavimentaram o caminho para o florescimento das políticas econômicas monetaristas, o que, em sua visão, marcou a instituição de um novo paradigma de política econômica ${ }^{5}$. E o novo paradigma não se institucionalizou apenas mediante a introduçáo de novos instrumentos de política econômica, mas principalmente pelas mudanças nos objetivos a serem almejados pelas referidas políticas. No caso do Reino Unido, a busca pelo pleno emprego, que até então era o grande objetivo da política econômica do Pós-II Guerra Mundial, foi "deixada de lado", cedendo espaço para as políticas de controle da inflaçáo, meta atingida por meio da manutenção de altas taxas de desemprego, o que mostra a natureza radical do processo de instituição do novo paradigma ${ }^{6}$.

4 As políticas econômicas keynesianas da sintese neoclássica que atuavam em um contexto de rigidez salarial passaram a dar sinais de esgotamento, na medida em que não conseguiam compensar esse fenômeno mediante políticas fiscais expansionistas. Com isso e devido à impossibilidade de redução dos salários dos trabalhadores - em virtude da forte mobilização dos sindicatos -, as taxas de desemprego começaram a se elevar, já que as políticas fiscais agravavam ainda mais os efeitos inflacionários gerados pelo aumento do preço internacional do petróleo, com efeitos negativos sobre a produção. Dessa forma, o trade off entre inflação e desemprego verificado na Curva de Phillips foi abandonado, já que as economias centrais passaram a conviver com altas taxas de inflação e desemprego, fenômeno que ficou conhecido como stagflação.

5 A abordagem de Hall (1990) parte do pressuposto de que as ideias possuem um papel fundamental na difusão e consolidação das políticas, sendo estas concebidas como um aprendizado (policy learning). Nesse sentido, os formuladores de politicas atuam no âmbito de um conjunto de ideias que especificam não apenas os objetivos das políticas e os seus instrumentos de atuação, como também revelam a natureza dos problemas que propiciaram o desenvolvimento de tais ideias. A esta relação, entre o contexto específico de desenvolvimento das ideias e a sua difusão através das políticas, o autor chama de paradigma de política (policy paradigm). Um novo paradigma de política se impõe na medida em que a natureza dos problemas a serem resolvidos se transforma, eliminando, dessa forma, o antigo paradigma, já que as ideias que alimentam a elaboração de suas políticas não são efetivas na resolução dos novos problemas. Em outras palauras, a difusão das ideias via aprendizado é a grande responsável pelas mudanças, sendo o contexto em que tais ideias floresceram fundamental para garantir a consolidação do novo paradigma.

6 A aceitação de altas taxas de desemprego pelo governo Thatcher se deveu ao fato de esta reduzir o potencial de consumo da população trabalhadora, o que reduziria a pressão inflacionária. Este procedimento, em conjunto com as tentativas de redução dos gastos públicos mostra que o foco das políticas estava fortemente centrado no controle inflacionário, a despeito da piora nas condições de vida da população. 
O Gráfico 1 evidencia essa tendência, ao mostrar o comportamento das taxas de desemprego e inflaçáo no Reino Unido entre 1980 e 1997, ou seja, durante todo o período de governo conservador. Nota-se um comportamento inverso entre as taxas de desemprego e os níveis de inflação, sendo a queda destes últimos acompanhada pela elevação do primeiro. Esse processo pode ser evidenciado da seguinte forma: entre 1980 e 1985, há uma queda expressiva da inflação, mas as taxas de desemprego atingem seus maiores níveis; entre 1986 e 1990, as taxas de desemprego caem, impulsionando a elevação da inflação; e, entre 1990 e 1994, quando novamente as taxas de inflaçáo caem significativamente, as taxas de desemprego voltam a subir ${ }^{7}$. Fraser $(2009$, p. 307) sintetiza bem esse período de governo conservador na seguinte afirmação: "Unprecedently, this government used the level of unemployment as an economic tool to contain inflation".

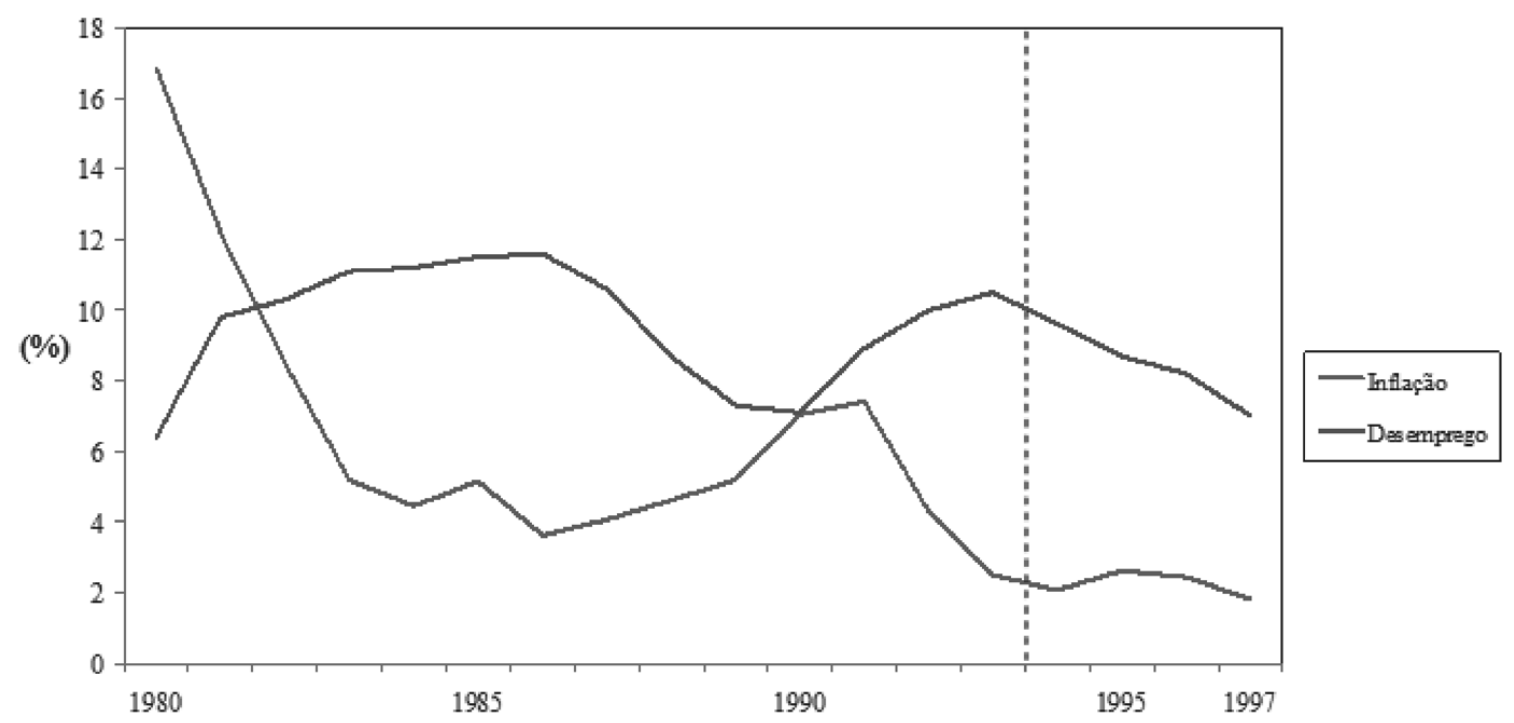

\section{Gráfico I - Taxas de desemprego e inflação - Reino Unido (1980-1997)}

Fonte: Para Inflação: estatísticas do FMI; para Desemprego: estatísticas da OIT

7 O Período 1994 a 1997 marcou o início de um novo ciclo de crescimento na economia Britânica, que se seguiu até pelo menos 2005. Os ajustes promovidos no início dos anos 1990, com o objetivo de combater a crise econômica que se instalou no país - em especial no mercado imobiliário - criaram as bases, segundo autores como Lund (2008) e Faucher-King e Le Galès (2010) para um crescimento que mesclava baixas taxas de inflação com reduzidos niveis de desemprego. Este "fenômeno", segundo os referidos autores, foi produto não apenas das políticas implementadas pelo governo conservador no período que seguiu a retirada no Reino Unido do Sistema Monetário Europeu, em 1992, que teve como objetivo desvincular o sistema de câmbio britânico do European Exchange Rate Mechanism - o que permitiu a flutuação das taxas de câmbio. O cenário econômico internacional também favoreceu a melhoria destes indicadores. Ambos estão na origem do sucesso das políticas econômicas implementadas pela gestão do Novo Trabalhismo a partir de 1997 (GIDDENS, 2005). 
Outra medida tomada pelo governo Thatcher foi a tentativa de controlar os gastos governamentais, apontados como um dos grandes responsáveis pelo lento crescimento da economia britânica desde o Pós-II Guerra Mundial. De fato, como aponta Glennerster (2007), os sucessivos governos conservadores neste período tentaram, sem sucesso, controlar o ritmo de crescimento dos gastos do governo, em especial os gastos sociais. Como, no entanto, o contexto político e social náo permitia que tais medidas fossem tomadas, os gastos continuaram a crescer, o que representava, para os críticos do Estado de Bem-Estar um deslocamento de recursos da atividade produtiva. Com a crise, tais argumentos ganharam força, sendo a mudança de paradigma de política econômica a "peça" que faltava para que tais medidas fossem tomadas.

Os fatos, no entanto, mostram que as tentativas de aplicação das políticas neoliberais, capitaneadas pela política econômica monetarista, apresentam contradiçóes, que estão relacionadas a própria lógica de funcionamento do capitalismo. Em primeiro lugar, embora tentativas tenham sido feitas no sentido de criar um sistema econômico completamente desregulamentado, o governo Thatcher "não abriu mão" de um aumento nos gastos governamentais, como forma de dar prosseguimento às reformas estruturais, o que pode ser conferido no Gráfico 2. Nesse sentido, entre 1980 e 1985 os gastos do setor público atingiram os maiores percentuais dentro da série histórica apresentada.

É importante frisar que, embora as referidas proporçóes de gastos tenham sido reduzidas no período 1985-1990, elas não caíram abaixo do que foi observado no período anterior à chegada dos conservadores ao poder, o que contradiz o argumento sobre os excessivos gastos governamentais no Reino Unido, já que os próprios defensores das políticas monetaristas não conseguiram reduzi-lo. Para reforçar ainda mais esse argumento, é fundamental mostrar que o gasto do setor público entre 1979 e 1997 foi, em média, 41,2\% do PIB, proporçáo superior aos 35,1\% no período 1965 e 1979. Mesmo quando se exclui o período em que os gastos do setor público atingiram a maior proporção do PIB (1980-1985), a média continua mais alta do que no período anterior a 1980 , chegando a $38 \%$. 


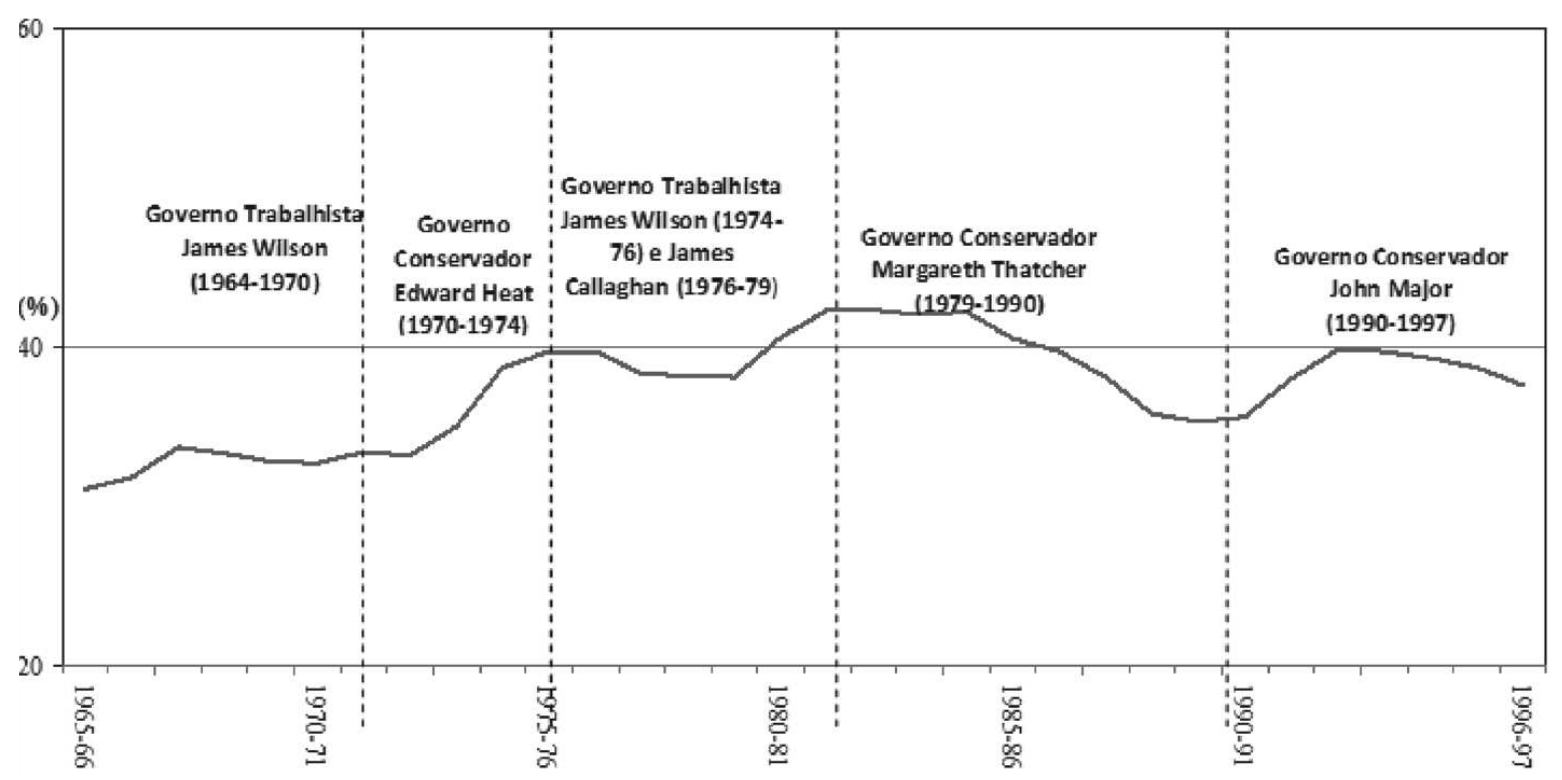

Gráfico 2 - Gastos Governamentais em relação ao PIB - Reino Unido (1965-1997)

Fonte: HM Treasury 2012

Da mesma forma que não houve redução efetiva dos gastos governamentais, os gastos com as políticas sociais também não sofreram redução - aumentando, inclusive, em alguns períodos -, o que se deve aos efeitos dos ajustes estruturais promovidos pelo governo conservador. Nesse sentido, enquanto em 1980 os gastos sociais representavam 35,9\% dos gastos totais no Reino Unido, em 1985 esses gastos representavam 42,6\%, chegando, em 1995, a representar 45,8\% (OCDE, 2012). Da mesma forma, de acordo com informaçóes fornecidas pelo "Institute for Fiscal Studies" do Reino Unido, os gastos com benefícios em relação ao PIB apresentaram suas maiores proporçóes durante a Era Thatcher. Só para se ter uma ideia, enquanto em 1980 essa proporção era de 9,9\% dos PIB, em 1994 ela chegou a 14,3\% (IFS, 2012).

O processo de ajuste e reestruturaçáo ao longo dos anos 1980 gerou transformações significativas na estrutura da economia e da sociedade britânica, o que demandou o aumento da intervençáo social do Estado. A ausência de elos que canalizassem os ganhos na esfera financeira para a produtiva 
gerou a retração da atividade industrial ${ }^{8}$, e concomitantemente um crescimento expressivo dos serviços financeiros. $\mathrm{O}$ resultado desse processo pode ser notado no aumento dos diferenciais de rendimento da população britânica, fenômeno que foi agravado com os ajustes feitos nos benefícios concedidos aos aposentados e à população em situação de vulnerabilidade social que passaram a ser indexados não mais aos reajustes salariais, mas corrigidos pela inflação. Da mesma forma, houve piora nos indicadores de desemprego e desigualdade social. Tavares (1993) sintetiza bem esse período na seguinte afirmação:

[...] os dois países anglo-saxões (Reino Unido e Estados Unidos), antigos líderes da tradição liberal-democrática, produziram, a partir da liderança ideológica de suas burocracias "imperiais" e de seus bancos internacionais, uma versão conservadora e excludente do processo de ajuste e modernização, com efeitos negativos inclusive em suas próprias sociedades nacionais. O predomínio excessivo que tiveram os interesses financeiros na condução das políticas de ajuste macroeconômico atingiram, sobretudo, os países periféricos, mas atrasaram também a reestruturação dos centros tradicionais. Por outro lado, uma visão liberal-conservadora aplicada às relações industriais entre capital e trabalho produziu uma considerável heterogeneidade nos "mercados de trabalho" e a rejeição das políticas de bem-estar minou os fundamentos de "justiça social” $e$ igualdade de oportunidades no interior de suas sociedades nacionais. (TAVARES, 1993, p. 23, grifo nosso).

O Gráfico 3 ilustra essa questáo, ao mostrar o comportamento dos indicadores sociais e dos gastos sociais no início e no final da Era Thatcher. Como fica demonstrado, há uma piora nas condiçóes de vida da população, com aumento da desigualdade de renda, da pobreza relativa e pobreza relativa infantil entre 1979 e 1995. Esse fenômeno, no entanto, vem acompanhado pelo aumento dos gastos sociais, medido em proporçáo do PIB e em relação aos gastos totais. Os gastos com benefícios sociais também cresceram consideravelmente durante esse período, o que indica que a piora nas condiçóes de vida da população demandou um aumento na intervenção social do Estado.

8 De acordo com informações levantadas por Kuner (2007), o emprego industrial, com relação ao total da força de trabalho britânica, caiu de 36,4\% para 24,9\% entre 1979 e 1995. Já o emprego no setor de serviços, como proporção da força de trabalho, elevou-se de $55,3 \%$ para $64,1 \%$. 


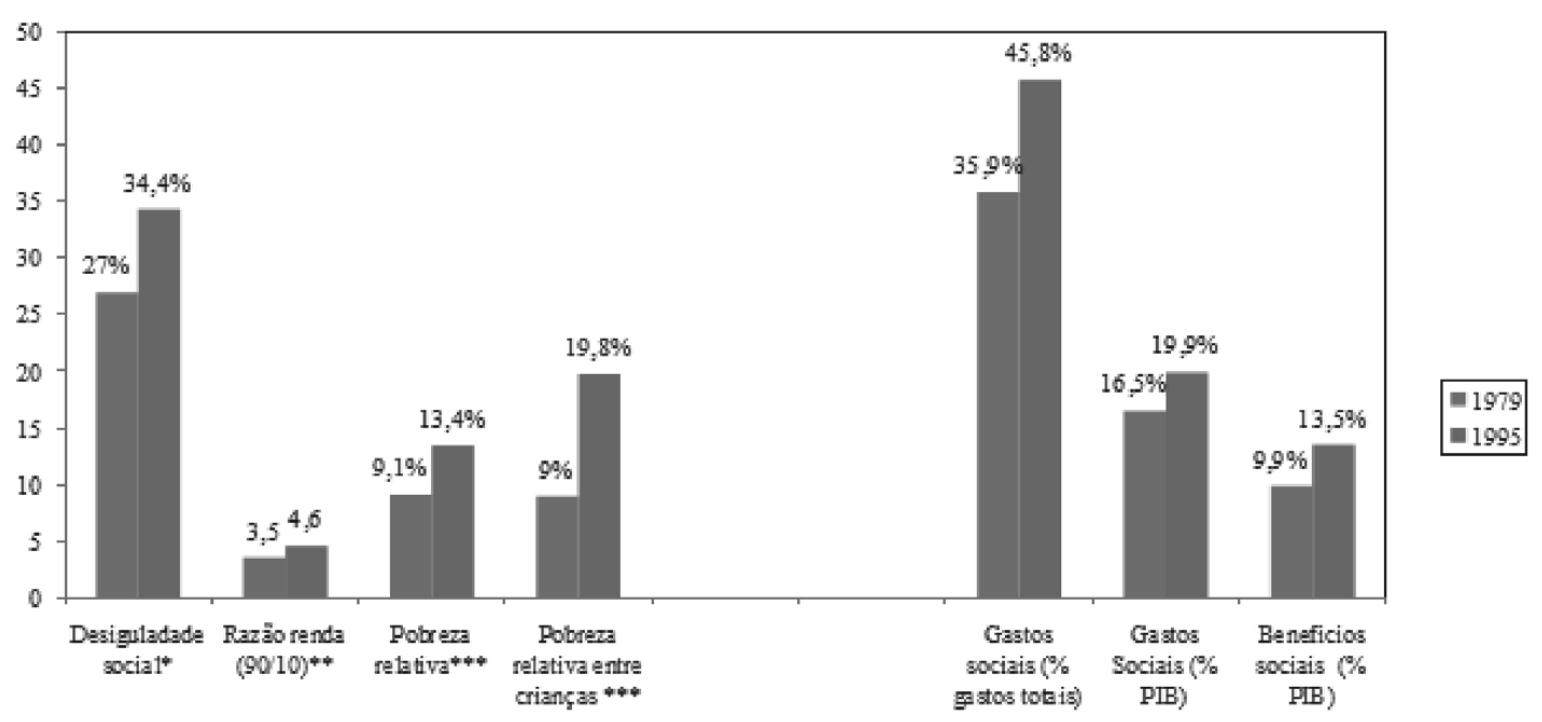

Gráfico 3 - Proporção de alguns indicadores sociais e de gastos sociais e benefícios sociais - Reino Unido (1979-1995)

Fonte: Luxembourg Study. CECD (Stat sxtract); Institute of Fiscal Studies (IFS)

* Índice de Gini (em percentual); ** Razão entre a renda dos 10\% mais ricos e 10\% mais pobres; *** Percentual da população com renda abaixo de 50\% da renda mediana

Dessa forma, a tentativa de efetiva redução dos gastos governamentais não foi observada durante a Era Thatcher - como evidenciado no Gráfico 2, o que indica duas ordens de fatores:

O primeiro deles se deve à necessidade de fortalecimento do Estado como forma de amortecer os impactos dos processos de ajustes estruturais ( $\mathrm{RO}$ DRIK, 1998). Nesse sentido, o governo conservador não apenas aumentou os gastos governamentais, mas promoveu uma série de reformas no sentido de fortalecer o poder central, fator relevante no processo de reestruturação das instituições econômicas e sociais (FAUCHER-KING; LE GALÈS, 2010).

O segundo fator se deve às deficiências de uma economia desregulamentada, que passou a demandar maior intervençáo social do Estado - na sua modalidade compensatória -, de forma a corrigir as imperfeições do mercado e a compensar a deterioraçáo do emprego e da renda. Esse fator é de fundamental importância para o presente estudo, pois mostra a impossibilidade histórica de formação de uma economia de mercado autorregulável. Os processos de desregulamentação dos mercados financeiros e de reestruturação econômica, aliados à tentativa de redução dos gastos governamentais e sociais, em especial, 
geraram uma significativa piora nas condiçóes de vida da população, obrigando o Estado a aumentar - e não diminuir - sua intervenção no campo social, como forma de garantir a continuidade do processo de acumulação de capital.

Por outro lado, o ajuste produtivo impingiu uma reestruturação em algumas das políticas sociais, o que pode tê-las levado a exercerem funçôes diferentes das que desempenhavam no período anterior à década de 1980 . Dessa forma, o superdimensionamento da esfera econômica - via fortalecimento das políticas monetárias e fiscais restritivas, dos mercados financeiros e da mudança nas características dos Estados nacionais - enfraqueceu o papel das políticas sociais nas estratégias de desenvolvimento dos países. Sua submissão à lógica das políticas econômicas reduziu, em um primeiro momento, seu escopo de atuação, que se deslocou, por sua vez, para o âmbito das intervençóes residuais.

De fato as políticas sociais sofreram uma significativa reestruturação, o que implicou mudanças em sua natureza, cuja principal característica está no enfraquecimento de seu papel em garantir elevados níveis de desmercantilização da vida social, por meio da adoção de políticas preventivas. Houve, por outro lado, o fortalecimento de sua função compensatória, o que implicou a adoção de políticas sociais que atuavam apenas quando o mercado apresentava ineficiências, fato este que justifica a execução de políticas residuais ex post. A próxima seção explora com mais profundidade essa questão, a partir da análise das relaçóes entre as políticas econômicas e sociais em um contexto de transformaçóes substanciais na organização da economia e da sociedade britânicas.

\section{Políticas econômicas e políticas sociais na Era Thatcher}

Ao contrário do período Pós-II Guerra Mundial, em que a busca pelo pleno emprego impingiu uma significativa articulação positiva entre as políticas econômicas e sociais no Reino Unido e no restante da Europa, a Era Thatcher foi marcada pelo rompimento desses elos, na medida em que o foco central das políticas econômicas passou a ser o controle inflacionário. Em outros termos, o estabelecimento de um novo paradigma de política econômica modificou as relaçóes com as políticas sociais, dentro de uma concepção teórica que concebe a esfera econômica não apenas separada, mas também antagônica, à esfera social. Como resultado, as políticas sociais passaram a ser consideradas 
um custo, sendo todas as tentativas de reestruturação e de controle dos gastos sociais necessárias à obtenção do equilíbrio macroeconômico.

De fato, como foi mencionado anteriormente, o aumento da vulnerabilidade social da população, decorrida dos efeitos dos ajustes econômicos, não foi compensada por um incremento no ritmo de crescimento dos gastos sociais. Isso basicamente devido ao fato de os adeptos do novo paradigma de política econômica náo considerarem as políticas sociais como um vetor estratégico no processo de acumulação do capital, o que inibiu a efetiva formaçáo de um novo modo de regulaçáo, o qual forneceria sustentabilidade às transformaçóes estruturais pelas quais a economia britânica vinha passando. $\mathrm{O}$ fato de as políticas neoliberais atribuírem dissociação entre as esferas econômica e social, bem como de conceberem o capitalismo como restrito às relaçóes estabelecidas no mercado, produziram o superdimencionamento da primeira, que passou a submeter as políticas sociais à sua lógica de funcionamento.

Em outros termos, seguindo a lógica das políticas neoliberais, promoveu-se descolamento da esfera econômica em relaçáo à esfera social. As consequências sociais desse processo, no entanto, não permitiram que as políticas sociais fossem desmanteladas. Embora o novo paradigma econômico as concebesse como um custo, elas se mantiveram centrais, em virtude das consequências que essa degradação das condiçóes de vida da população poderia impingir sobre o processo de reproduçáo do capitalismo. Em outras palavras, a ameaça de rompimento dos vínculos políticos e sociais, formados durante o processo de institucionalização do Welfare State e que garantiram altos níveis de coesão da sociedade britânica durante mais de 30 anos, tornou mais do que evidente o lugar central que o Estado ocupava no sistema capitalista. Polanyi (2000) resume bem esse processo na seguinte passagem:

[...] um sistema de mercado autorregulável implica [...] mercados para os elementos da produção - trabalho, terra e dinheiro. Quando o funcionamento desses mercados ameaça destruir a sociedade, a ação autopreservativa da comunidade visa a impedir seu estabelecimento ou interferir com o seu livre funcionamento, quando já estabelecido. (POLANYI, 2000, p. 237, grifo nosso).

Diante da impossibilidade de criar uma economia de mercado autorregulável, os formuladores de políticas passaram a defender a reestruturaçáo das políticas sociais, ao invés de promoverem seu desmonte, o que implicava a 
elaboração de políticas que não comprometessem o equilíbrio macroeconômico. Essa reestruturação, entretanto, objetivou fortalecer o papel mais restrito das políticas sociais, já que estas teriam a função de garantir a eficiência do sistema econômico, com a correção das falhas de mercado - o que implicava a adoção de políticas residuais. Em outras palavras, objetivava-se impingir uma articulação entre as políticas econômicas e sociais, e estas últimas estariam completamente submetidas à lógica de funcionamento do sistema econômico, em um movimento diferente do observado no Pós-II Guerra Mundial, quando a incorporaçáo dos direitos sociais à cidadania moldou náo apenas o formato das políticas sociais, influenciando também o tipo de articulação com as políticas econômicas.

De acordo com Glennerster (2007), o referido processo de reestruturaçáo só começou a "ganhar peso" a partir de meados da década de 1980, com a terceira vitória conservadora, a qual foi seguida pela implementação de uma série de legislaçóes que visavam à reformulação das políticas sociais. Entre elas, destacam-se: o Social Security Act, de 1986; o Housing Act e o Educational Reform Act, de 1988; o National Service and Community Care Act, de 1990; e as reformas no setor de saúde que estavam contidas no White Paper Working for Patients, de 1989. Em linhas gerais, esses atos visavam à "desregulamentação" das políticas sociais, ou seja, o Estado náo seria o único provedor dos serviços sociais, abrindo espaço para a participaçáo do setor privado (que atuaria tanto na provisão dos serviços, como na habitação e nos planos de aposentadoria), como na parceria com o Estado (caso do setor de saúde e da assistência social).

Na primeira metade da década de 1980, o governo estava mais preocupado com a reestruturação econômica, ficando as políticas sociais em segundo plano. $\mathrm{O}$ aumento na vulnerabilidade social da população, no entanto, trouxe consigo o incremento nos gastos sociais do governo, o que era uma contradição em relaçáo às políticas de austeridade fiscais, criando um paradoxo ${ }^{9}$, que o governo só conseguiria resolver caso conjugasse a política social aos requisitos

9 Esse paradoxo está no cerne da obra de Polanyi (2000) e se refere à incompatibilidade entre, de um lado, a implantação das políticas neoliberais que defendem a desregulamentação da economia e a redução da intervenção social do Estado e, de outro, os efeitos perversos que tais políticas trazem para as condições sociais da população, o que força o retorno das políticas sociais. Em outras palauras, esse paradoxo se refere ao um movimento dual, no qual o avanço das forças de mercado produz uma reação das instituições políticas $e$ sociais, que tentam freá-lo, reduzindo seus efeitos sobre as condições de vida da população. 
de uma política econômica contracionista. A passagem de Glennerster (2007) ilustra bem aquela conjuntura:

The government wanted to achieve cuts in the largest programme of public expenditure but its own economic policy was increasing people's dependency on benefits. It wanted to increase the targeting but it found that the extent targeting was already considerable and was creating disincentives to work. It probably wanted to means test pensions but incautious remarks by the Chancellor to that effect caused such a hostile reaction that the idea was dropped. Social policy was an altogether harder nut to crack. (GLENNERSTER, 2007, p. 190, grifo nosso).

Dessa forma, a estratégia do governo foi realizar uma série de reformas, com o objetivo de transformar a estrutura do Welfare State, cujo funcionamento seria vinculado à lógica de mercado. A ideia era introduzir formas de gestão privada no âmbito da prestaçáo de serviços públicos, o que significava, em outros termos, o aumento da competitividade e, por conseguinte, da eficiência do sistema. Para Le Grand (1991), essas reformas objetivaram a introdução de mecanismos de "quase-mercado" (quasi-market) ${ }^{10}$ na provisão dos serviços públicos, o que significava que o Estado não seria mais o financiador e o provedor das políticas sociais, ficando principalmente com a primeira das funçóes. A provisáo dos serviços públicos ficaria a cargo de fundaçóes e entidades privadas que competiriam entre si pelos recursos disponibilizados pelo Estado.

A implementação das referidas reformas pode ser compreendida dentro de um horizonte temporal marcado por três fases:

A primeira delas abrangeu os anos de 1979 a 1986, período no qual as políticas sociais tiveram importante papel em amortecer os impactos do processo de ajuste econômico. As altas taxas de desemprego, em conjunto com as reformas feitas nas políticas habitacionais, contribuíram para que a participação dos gastos sociais no PIB passasse de 16,5\% em 1980 para 19,4\% em 1985 (Gráfico 4). Pela análise do Gráfico 4, observa-se, nessa primeira fase,

10 O termo quase-mercado se refere ao fato de que as transações não almejam o lucro aferido no mercado, mas sim os resultados em termos de eficiência do sistema. Le Grand (I99I, p. 126) apresenta a seguinte definição para o termo quase-mercado: "All these developments thus involve the introduction of quasi-markets into the welfare state. They are 'markets' because they replace monopolistic state providers with competitive independent ones. They are 'quasi' because they differ from conventional markets in a number of key ways". 
uma piora nos indicadores sociais (com exceção da pobreza relativa), cujo desempenho, entretanto, foi melhor do que o observado no período subsequente, marcado pela introdução de políticas de ajuste no campo social.

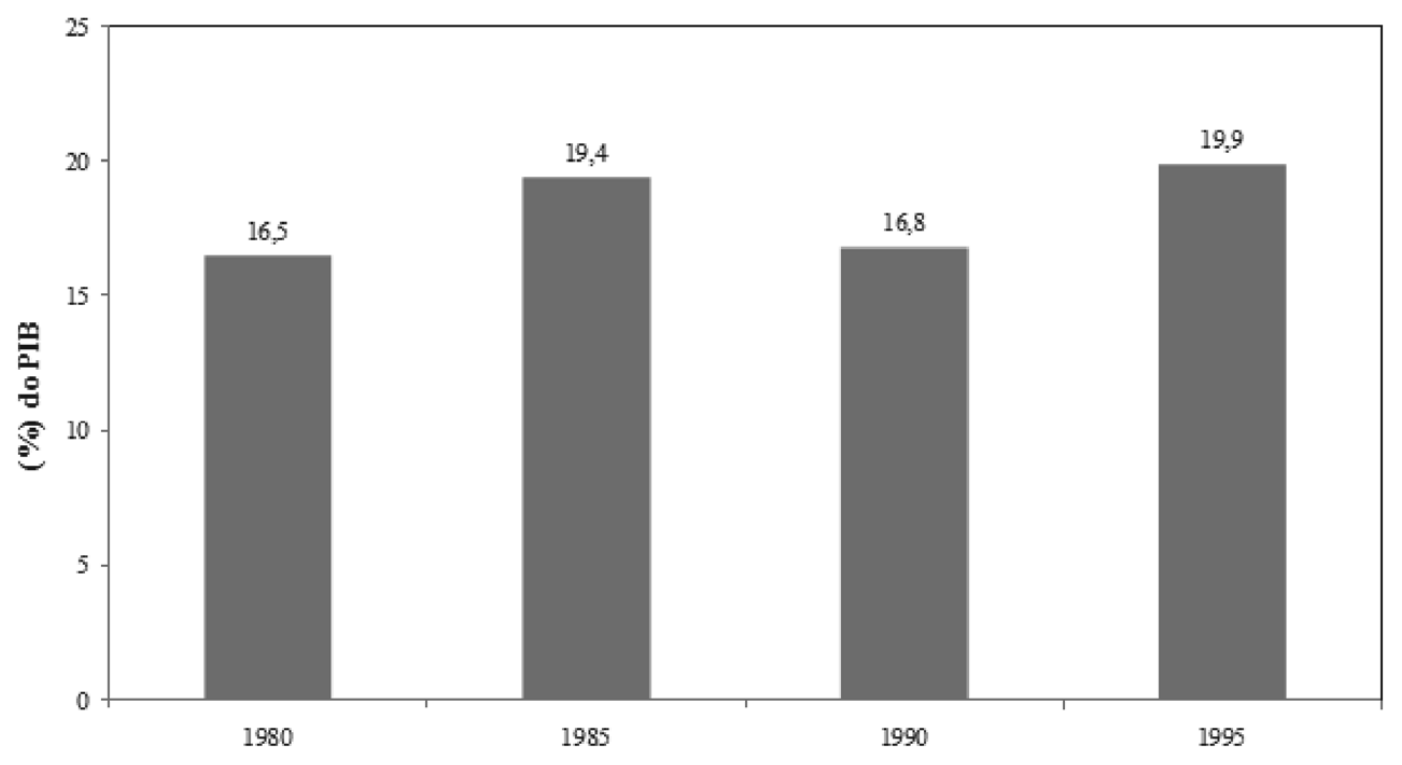
Gráfico 4 - Proporção dos gastos sociais em relação ao PIB - Reino Unido (1980-1985)
Fonte: Estatísticas da OCDE

A segunda fase abrange anos de 1986 a 1991 e se caracteriza por uma reação ao aumento dos gastos sociais da fase anterior, a qual originou o processo de reestruturaçáo das políticas sociais. Devido ao paradoxo gerado pela implementação das políticas neoliberais, o governo já sabia que não haveria como "abrir mão" das políticas sociais, visto que o melhor caminho estaria na sua submissáo à lógica das políticas econômicas, com o objetivo de reduzir os gastos, por um lado, ainda que mantendo uma extensa cobertura. A efetividade da política contracionista do governo nesse período pode ser vista no ritmo de crescimento dos gastos sociais, que sofreu uma retração anual de $0,2 \%$, com a participaçáo dos gastos sociais no PIB caindo para 16,8\% em 1990 (Gráfico 4). Ocorre, no entanto, que o processo de reestruturação das políticas sociais do período não promoveu uma melhoria nas condiçóes de vida da população. Pelo contrário, houve uma piora nos indicadores sociais, em especial no que se refere ao avanço da pobreza relativa e da pobreza relativa infantil - como mostra o Gráfico 5-, o que sugere que o referido processo não correspondeu 
aos postulados básicos de eficiência de mercado, na medida em que buscou o controle dos gastos sociais em um momento em que o país passava por intensas transformações na esfera econômica.

A terceira fase (1991-1995) pode ser compreendida como uma resposta aos efeitos da restriçáo dos gastos sociais realizada entre 1985 e 1990 . O aumento nos níveis de desigualdade de renda e pobreza, verificados no período anterior, forçaram o governo a intensificar a participação dos gastos sociais no PIB, que alcançaram os maiores percentuais da Era Thatcher (cerca de 20\%) em 1995 (Gráfico 4). Essas medidas podem ser compreendidas como uma resposta à ineficácia de se tentar submeter as políticas sociais à lógica de funcionamento de um paradigma de política econômica que não atribui importância central para a intervenção social do Estado.

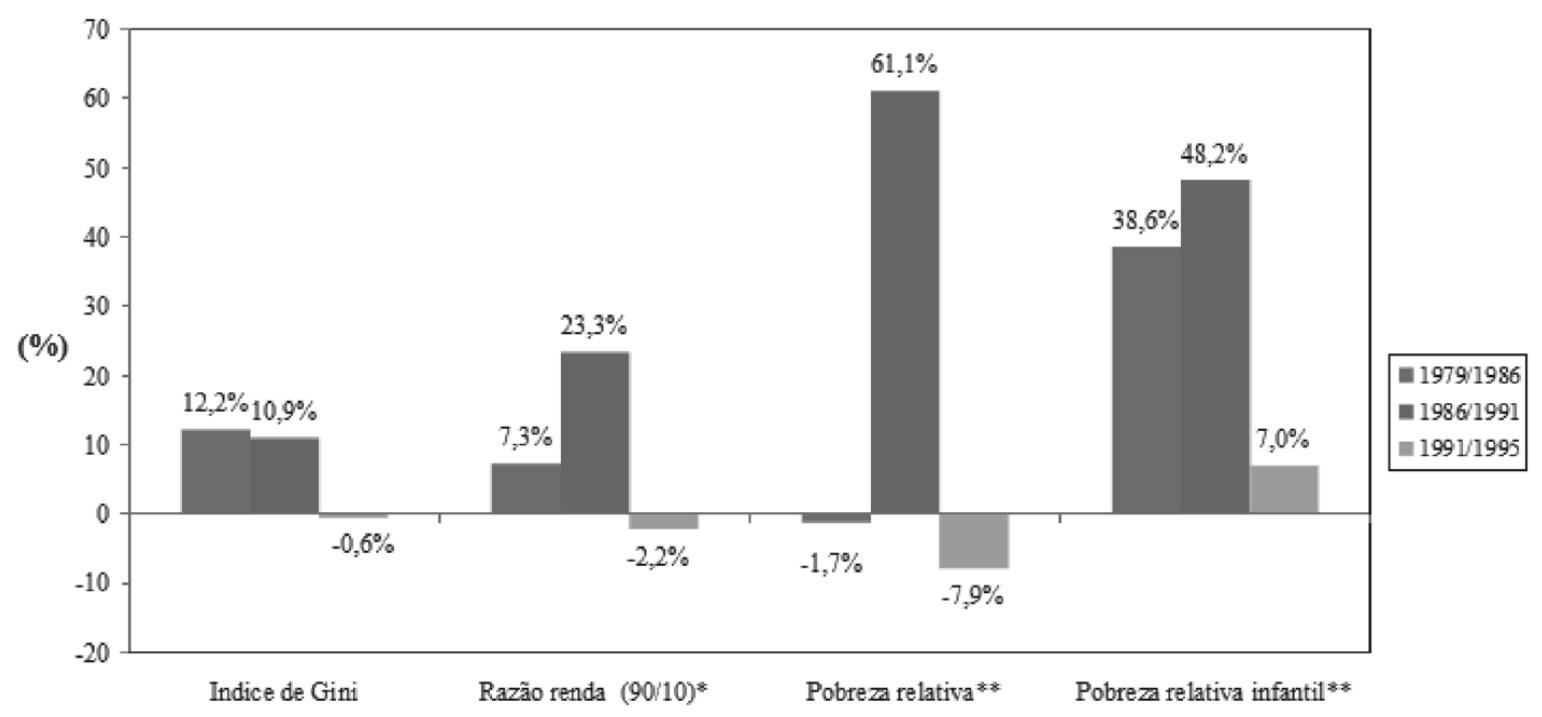

\section{Gráfico 5 - Variação relativa de indicadores sociais em três momentos na Era Thatcher}

Fonte: Luxembourg Icome Study. CECD (Stat sxtract); Institute of Fiscal Studies (IFS)

* Razão entre a renda dos 10\% mais ricos e 10\% mais pobres; ** Percentual da população com renda abaixo de $50 \%$ da renda mediana

Cabe ressaltar que esse período foi marcado não apenas pela queda da Primeira Ministra Margareth Thatcher", como também pela reversão e

II A Primeira Ministra Margareth Thatcher renunciou em 1990, após três vitórias eleitorais consecutivas. Entre os motivos para sua renúncia, destacam-se: a queda nos niveis de popularidade, devido à adoção de medidas 
reformulação de algumas políticas que haviam sido rejeitadas pela população (FRASER, 2009). Dessa forma, o novo governo, liderado pelo Primeiro Ministro John Major, foi "induzido" a aumentar os gastos sociais com o objetivo de reduzir os níveis de desigualdade social e pobreza, o que foi conseguido (Gráfico 5) - com exceção da pobreza relativa infantil -, embora eles se mantivessem em patamares elevados, quando comparados com o período anterior a 1980 (Gráfico 3).

É importante frisar que o governo John Major não rompeu com o modelo de políticas sociais desenvolvido na Era Thatcher, ou seja, o aumento dos gastos sociais ocorreu em conjunto com o aprofundamento das práticas de mercado introduzidas no âmbito de uma série de políticas. Ao contrário do governo anterior, no entanto, não houve a busca pela redução dos gastos, tendo o governo se preocupado mais com a estrutura dos investimentos, assim como as formas pelas quais as políticas sociais se articulariam com as políticas econômicas. Nesse sentido, abriu-se espaço, no âmbito das políticas econômicas restritivas, para o aumento dos gastos sociais, na medida em que sua importância se mostrava fundamental para a continuidade das reformas no campo econômico.

Esse processo, no entanto, só ocorreu nos anos finais da Era Thatcher. Ao longo de todo o período, foi conferida uma prioridade ao processo de reestruturação econômica, o que produziu profundas transformaçóes na economia e sociedade britânicas. Mesmo as medidas que resultaram na reduçáo da vulnerabilidade social, adotadas no governo John Major, não foram capazes de colocar os indicadores sociais em patamares semelhantes ao observado no período anterior a 1980. As reformas econômicas, por sua vez, não lograram os resultados esperados, visto que o processo de desindustrialização não atingiu apenas a organização sindical, ele enfraqueceu ainda mais a já frágil base econômica britânica, capturada, após as reformas, por conglomerados financeiros cada vez mais internacionalizados.

A próxima seção especifica, com mais detalhes, a reestruturação das políticas sociais a partir do estudo de caso da política de manutenção da renda.

que beneficiavam os ricos em detrimento dos pobres; e as disputas no interior do Partido. Ela foi sucedida pelo então Chanceler John Major, que se tornou Primeiro Ministro ao derrotar os Trabalhistas na eleição de 1992. levando os Conservadores a governarem o Reino Unido por mais cinco anos. 


\section{A política de manutenção da renda}

De acordo com Glennerster (2003), os objetivos que guiam a formulaçáo das políticas de renda refletem duas naturezas distintas. A primeira delas, defendida pelos seguidores do neoliberalismo, atribui ao Estado a função de aliviar a pobreza, mediante políticas residuais que concedam uma renda "temporária" - àqueles indivíduos que não estejam ganhando o mínimo necessário para sua sobrevivência. Essa visão retira do Estado a responsabilidade de garantir uma renda mínima para todos os cidadáos, promovendo equidade, repassando-a aos indivíduos, dentro da ideia de que cada um é responsável por si. Além disso, o mercado é considerado o lócus no qual os recursos são alocados de forma mais eficiente, o que, traduzido para as políticas de manutençáo da renda, significa que ele proporciona oportunidades para que todos possam, em tese, acumular recursos para a aposentadoria.

A segunda intencionalidade coloca no Estado a responsabilidade de garantir uma renda às pessoas que, por algum motivo, se encontram em situaçáo de pobreza, pois consideram que o mercado apresenta falhas que só são corrigidas mediante intervenção estatal. Da mesma forma, o Estado tem a função de garantir que os indivíduos acumulem recursos para a aposentadoria, por meio da criação e da manutençáo de planos de seguro social compulsórios, o que garantiria, também, cobertura para o caso de se encontrarem desempregados.

O governo Thatcher teve início com a promulgação do Housing and Social Security Act, de 1982, que marcou a adoção de uma série de medidas que visavam não apenas à desregulamentação da política habitacional, mas também à restrição ao gasto com benefícios sociais. Nesse sentido, duas medidas foram tomadas: a primeira delas se referia ao corte de benefícios complementares, como o auxílio-doença e o auxílio-desemprego, ambos atrelados aos ganhos dos trabalhadores. Paralelamente a essa medida, os benefícios concedidos passaram a ser taxados, e seus reajustes passaram a ser indexados à inflaçáo e não mais aos ganhos dos trabalhadores da ativa. Essa mudança fez com que a taxa de reposição das aposentadorias e pensôes caísse ao longo do tempo, passando de 23\% em 1981 para 15\% em 1995 (FRASER, 2009).

A segunda medida está relacionada a mudanças nas formas de taxação, com a reduçáo da incidência do imposto sobre a renda e o aumento da taxação 
sobre o consumo, o que representou, em outras palavras, uma maior regressividade na estrutura tributária britânica. Cabe destacar, nesse sentido, que o incremento Value Added Tax objetivava compensar a queda na arrecadação, proporcionada pela reduçáo nas alíquotas do imposto sobre a renda.

Outra medida de caráter regressivo tomada pelo governo estava na progressiva redução da contribuição do governo para o seguro social - que, entre 1980 e 1990, passou de 18\% (do total) para zero -, juntamente com o aumento da contribuição individual (GLENNERSTER, 2007).

A implementação dessas medidas, no entanto, não reduziu os gastos com benefícios sociais do governo, já que houve aumento da demanda, em decorrência da deterioração das condiçóes de vida da população. $\mathrm{O}$ aumento do desemprego e do número de pessoas sem o mínimo necessário para sobreviver acabou elevando a demanda pelo seguro-desemprego e pelos benefícios de assistência social, a qual atingiu 5,6 milhóes de pessoas em 1993, cerca de cinco vezes mais do que o verificado em 1948 (FRASER, 2009). Cabe ressaltar, ainda, o incremento no volume de aposentadorias e pensóes, devido ao aumento absoluto da população idosa, em especial dos indivíduos com mais de 75 anos, que tiveram um crescimento de quase 34\% entre 1979 e 1997 (UNITED NATIONS, 2011).

O Gráfico 6 mostra que nos primeiros seis anos do governo Thatcher (1979-1985), a participação dos benefícios sociais no PIB passou de 9,9\% para $12,4 \%$, o que indica que as tentativas de redução dos gastos com benefícios não foram efetivas. O referido gráfico ilustra, ainda, que no período 1985-1990, houve redução na participação dos benefícios sociais em relação ao PIB, o que está relacionado à mudança de estratégia do governo, o qual, sabendo que não poderia cortá-los, passou a reestruturá-los. 


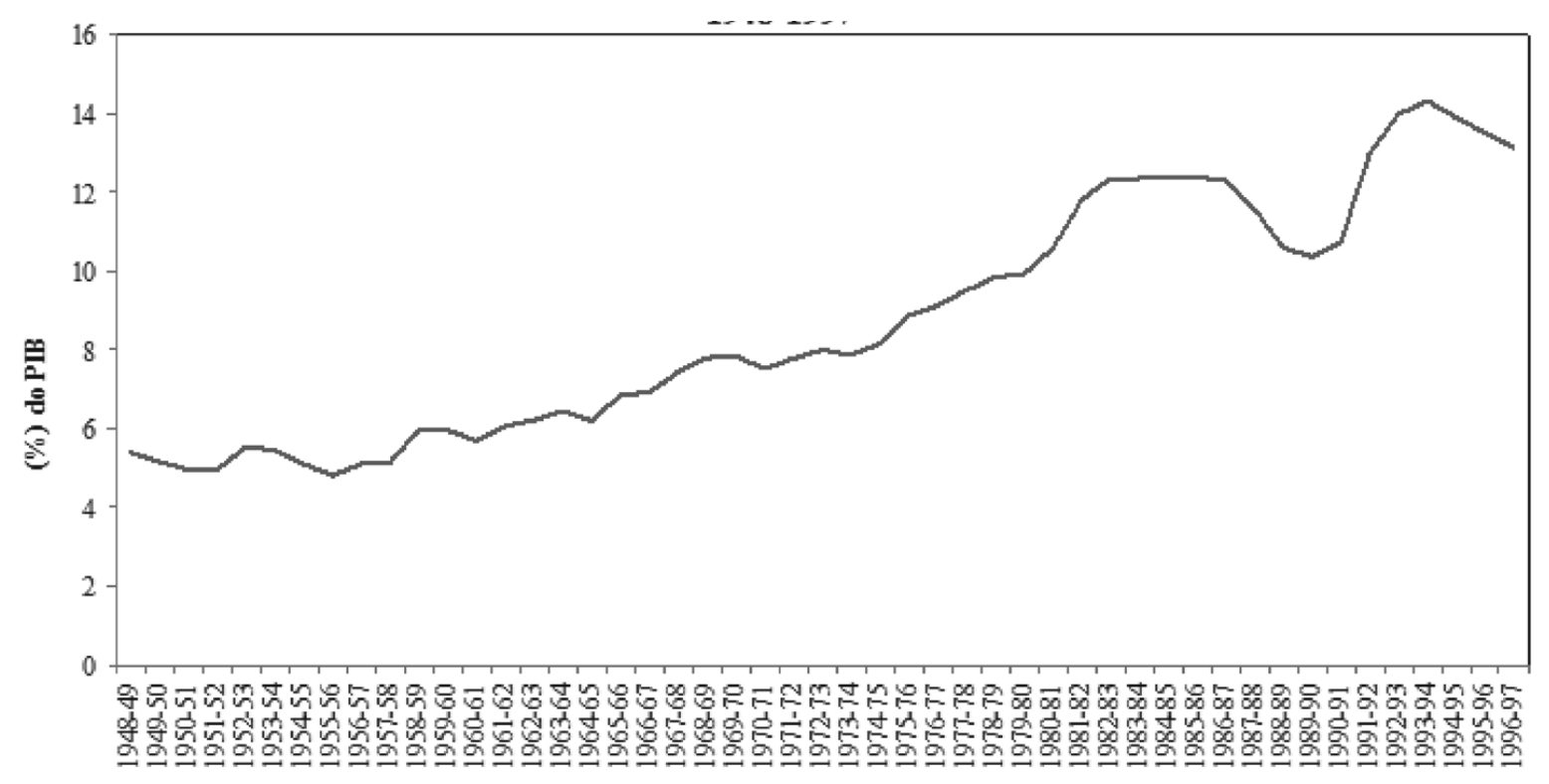

Gráfico 6 - Gastos em benefícios como proporção do PIB (1948-1997)

Fonte: Institute for Fiscal Studies

Nesse sentido, a promulgação do Social Security Act (1986) introduziu uma série de mudanças no formato dos benefícios, bem como nos seus critérios de elegibilidade. Em primeiro lugar, o governo procurou simplificar e padronizar as regras de acesso aos sistemas de benefícios means-tested, os quais operavam a partir de diferentes definiçóes. Em segundo lugar, foi realizada uma extensa reforma no sistema de seguro social, cujo principal objetivo era garantir maior espaço para os sistemas de previdência privados. A ideia do governo era manter a aposentadoria padrão (flat rate), incentivando os indivíduos (mediante renúncia fiscal - tax reliefs) a fazerem planos complementares junto à iniciativa privada. Esse processo permitiu que o governo reduzisse os investimentos no seguro social, passando a operar, basicamente, com a aposentadoria padrão. De acordo com Taylor-Gooby (1988), houve uma economia de mais de $50 \%$ com os "cortes" nos recursos do seguro social, já que pelas estimativas governamentais mais de $85 \%$ dos trabalhadores britânicos seriam membros, ao final do século XX, de planos de aposentadoria náo estatais.

De fato, as informaçóes levantadas por Glennerster (2003) e sistematizadas na Tabela 1, confirmam essas projeçóes, pelo menos para os trabalhadores do sexo masculino, com idade entre 65 e 69 anos. Em 2001, cerca de $80 \%$ deles eram beneficiários de planos privados de aposentadoria, os quais 
pagavam em média 36,6\% dos salários dos trabalhadores da ativa. Essa proporção é superior à taxa de reposição das aposentadorias públicas, cuja proporção é de $27,2 \%$. Na comparaçáo com os demais países, é interessante notar que, enquanto o Reino Unido apresenta a segunda maior taxa de reposição nas aposentadorias privadas, no caso da aposentadoria pública essa taxa é a menor.

Essas informaçóes confirmam claramente a estratégia do governo de dividir com o setor privado os custos com a provisão das aposentadorias. Isso, entretanto, não significou a mudança na natureza do sistema. Deve-se ressaltar que, ao longo do período Pós-II Guerra Mundial, algumas tentativas foram feitas com o objetivo de inserir a provisão privada de aposentadorias no âmbito do sistema, o que foi conseguido em parte, com o surgimento de alguns planos ocupacionais vinculados a empresas específicas. Mesmo na proposta original de Willian Beveridge (Beveridge Report), não havia oposição à provisão privada de seguro social, desde que o Estado assegurasse a todos os cidadáos uma aposentadoria básica (flat-rate). Isso fica evidente quando se observa que a magnitude dos gastos públicos em aposentadorias no Reino Unido é inferior ao observado nos principais países europeus ${ }^{12}$.

Tabela I - Indicadores de Cobertura de aposentadorias públicas e privadas: homens com 65 anos aposentados - Reino Unido (200I)

\begin{tabular}{|c|c|c|c|c|}
\hline \multirow{2}{*}{ Países } & \multirow{2}{*}{$\begin{array}{c}\text { Beneficiários } \\
\text { de Aposentad orias } \\
\text { Publicas } \\
(\%)\end{array}$} & \multirow{2}{*}{$\begin{array}{c}\text { Beneficiários } \\
\text { de Aposentadorias } \\
\text { privad as } \\
(\%)\end{array}$} & \multicolumn{2}{|c|}{$\begin{array}{c}\text { Taxa de Reposição das Aposentarias } \\
\text { vis a vis } \\
\text { População A tiva }\end{array}$} \\
\hline & & & $\begin{array}{l}\text { Aposentadoria } \\
\text { Pública }\end{array}$ & $\begin{array}{c}\text { Aposentadoria } \\
\text { Privada }\end{array}$ \\
\hline Alemanha & 100 & 16,4 & 79,3 & 4,6 \\
\hline Itália & 97,5 & 5,2 & 75 & 4,2 \\
\hline Holanda & 95 & 82,7 & 50,2 & 52,5 \\
\hline Suécia & 100 & 88,2 & 87,8 & 25,8 \\
\hline Reino Unido & 99 & 80,7 & 27,2 & 36,6 \\
\hline
\end{tabular}

Fonte: OECD (200Ic) Apud Clennester (2003)

Em 1989, além das mudanças que favoreceram a expansão da provisão privada de aposentadorias, o governo Thatcher introduziu um novo imposto, chamado de "Community Charge" e que seria responsável pelo financiamento

12 Só para se ter uma ideia, a participação dos gastos governamentais com aposentadoria, em relação ao PIB, não chegava a 5\% (4,8\%) no Reino Unido em 1990. Enquanto isso, países como Suécia, Alemanha, França tinham proporções superiores a 8\% (OCDE, 20I2). 
das autoridades locais. Esse imposto era uma espécie de Poll Tax, ou seja, incidia sobre cada indivíduo, o que era um retrocesso em relação à taxa anterior, que incidia sobre a propriedade. Em outras palavras, a introdução da Poll Tax tornou o sistema de taxas britânico ainda mais regressivo, haja vista o aumento da taxação sobre o consumo em detrimento da taxação sobre a renda. Só que nesse caso houve reaçáo da população que, insatisfeita com o aumento dos impostos, iniciou uma série de manifestaçóes que contribuíram para a saída da Primeira Ministra do poder em 1990.

A gestão do Primeiro Ministro John Major não foi marcada por significativas mudanças nas políticas de manutenção da renda. Além da supressão da Community Charge e da volta da taxação sobre a propriedade (Council Tax), suas medidas tiveram um caráter mais residual, ou seja, tentaram adequar o sistema de benefícios às características do novo regime econômico.

A primeira medida adotada por John Major foi a reformulação do seguro-desemprego, que passou a se chamar Job Seeker's Allowances em 1996. Os desempregados receberiam um benefício monetário por seis meses, caso continuassem a procurar trabalho ${ }^{13}$. Como será visto adiante, esse modelo foi aperfeiçoado pela gestão trabalhista a partir de 1997.

A segunda mudança foi a elevação dos gastos sociais, que foi tomada como forma de compensar as perdas oriundas da política de ajuste do período entre 1985 e 1990. Enquanto nesse último período os gastos sociais per capita tiveram redução de cerca de 1\%, entre 1990 e 1995 houve um crescimento de quase $29 \%$. Em relação às políticas de manutenção da renda, houve um aumento nos gastos com aposentadorias e pensóes (passaram de 4,8\% para $5,5 \%$ do PIB) e também nos gastos assistenciais (passaram de 2,2\% para 2,9\% do PIB) (OCDE, 2012).

Em suma, a política de manutenção da renda na Era Thatcher adquiriu feiçóes neoliberais, principalmente pela expansão da provisão privada de seguro social, mas também pela sistematização e padronização dos benefícios de caráter residual. A responsabilidade do Estado em garantir uma renda mínima para cada cidadáo ao final da sua vida ativa, no entanto, se manteve. Isso mostra a força da institucionalidade do sistema ${ }^{14}$. Cabe destacar, ainda, que

13 Essa reformulação também funcionou como uma forma de diferenciar os desempregados das pessoas que buscavam os beneficios de assistência social (Income Support). Como estes eram maiores do que o segurodesemprego, muitos desempregados preferiam pedir o benefício assistencial, o que contribuía para o aumento dos gastos. A reformulação do seguro-desemprego, por sua vez, dividiu claramente essas duas categorias.

14 É importante ressaltar que a aposentadoria básica e os demais benefícios sofreram redução nos seus valores, quando comparados com os ganhos da população ativa. Isto mostra claramente a estratégia do governo 
se, por um lado, a reestruturação dos benefícios e dos sistemas de taxas e impostos contribuiu para a redução dos gastos sociais, por outro, as consequências do ajuste produtivo aumentaram o número de indivíduos demandando benefícios sociais, tendo como resultado um aumento dos gastos ao final do governo conservador.

\section{Considerações finais}

Buscou-se mostrar, ao longo do presente artigo, as principais características do ajuste estrutural promovido pelo governo conservador britânico ao longo dos anos 1980, bem como suas relaçóes com as políticas sociais. É importante esclarecer, primeiramente, que o referido ajuste foi feito tendo como base a introduçáo de um novo paradigma de política econômica, que atribuía primazia ao mercado no funcionamento da economia capitalista. Nesse sentido, foram criadas várias medidas que visavam à desregulamentação do sistema econômico, em especial do setor financeiro, em detrimento da atividade estatal, esta considerada prejudicial à eficiência do capitalismo.

Na prática, no entanto, o que se observou foi uma mudança no padrão de intervenção do Estado, principalmente nos primeiros anos do governo Thatcher, evidenciado, inclusive, no aumento dos gastos governamentais. $\mathrm{O}$ mesmo foi notado para o caso dos gastos sociais, cujo crescimento esteve relacionado ao aumento da vulnerabilidade social da população nesse mesmo período, o que confirma a hipótese de Rodrik (1998), para quem a maior presença estatal é requerida em face do agravamento dos problemas sociais produzidos pelo processo de reestruturaçáo econômica.

Embora tenham demandado maior intervenção estatal, as medidas de ajuste econômico promoveram o superdimensionamento da esfera econômica, que passou a pressionar por reformulaçóes nas políticas sociais, cujas características deveriam se adequar aos requisitos de uma economia desregulamentada. Ocorre que, em essência, o novo paradigma de política econômica atribuiu às políticas sociais um papel residual, quando não prejudicial à eficiência do mercado, o que implicaria a reduçáo da sua influência no processo de reproduçáo do sistema. A soluçáo para esse paradoxo passou a ser a flexibilização das políticas econômicas restritivas, o que ocorreu principalmente durante o governo John Major, permitindo o avanço da reformulação das políticas sociais em conjunto com a expansão dos gastos sociais.

conservador de manter uma série de benefícios, concedendo-os como um aspecto residual, não substituivel aos ganhos do mercado de trabalho. 
Nesse sentido, as políticas sociais se mantiveram centrais no capitalismo britânico, adquirindo, por outro lado, uma feiçáo mercantilizada, ou seja, atribuiu-se primazia ao mercado na provisão da renda para os indivíduos. $\mathrm{Na}$ impossibilidade de que os cidadáos tivessem supridas suas necessidades de sobrevivência básicas pelo mercado, o governo passou a conceder benefícios residuais. Em outras palavras, observou-se, ao longo da Era Thatcher, uma mudança no padrão das políticas sociais, com uma redução de sua feição desmercantilizada acompanhada por um aumento de intervençóes compensatórias, por meio de transferências monetárias de renda condicionadas à existência de falhas.

\section{Referências}

BAER, M. et al. Os desafios à reorganização de um padrão monetário internacional. Revista Economia e Sociedade, Campinas, n. 4, p. 79-126, 1994.

CHANG, H. J. An Institutionalist Perspective on the Role of the State: Towards an Institutionalist Political Economy. In: Globalisation, Economic Development and the Role of the State. Penang: Third World Network; London: Zed Books, 2003. p. 75-103.

GLENNERSTER, H. British Social Policy: 1945 to the Present. Oxford: Blackwell Publishing, 2007. . Understanding the Finance of Welfare. Bristol: The Policy Press, 2003.

FAUCHER-KING, F.; LE GALÈS, P. The New Labour Experiment: Change and Reform Under Blair and Brown. Stanford: Stanford University Press, 2010.

FRASER, D. The Evolution of the British Welfare State. New York: Palgrave Macmillan, 2009.

GIDDENS, A. A Sociologia. Tradução de Sandra Regina Netz. 4. ed. Porto Alegre: Artmed, 2005.

GOUGH, I. The Political Economy of the Welfare State. London: MacMillan, 1979.

HALL, P. A [1950]. Policy paradigms, social learning and the state: the case of economic policymaking in Britain. Instituto Juan March de Estudios e Investigaciones, Centro de Estudios Avanzados en Ciencias Sociales, Madrid, 1990. Disponível em: <http://digital.march.es/ceacs-ir/ en/fedora/repository/ir\%3A3880>. Acesso em: 5 maio 2012.

INSTITUTE FOR FISCAL STUDIES (IFS). Fiscal Facts. 2012. Disponível em: <www.ifs.org. uk/fiscalFacts/taxTables>. Acesso em: 6 maio 2012.

KUNER, C. European data protection law: corporate compliance and regulation. 2nd. ed. New York: Oxford University Press, 2007. 
LE GRAND, J. Quasi-Markets and Social Policy. The Economic Journal, v. 101, n. 408, p. $1256-$ 1267, Sept. 1991.

LUND, B. Major, Blair and the Third Way. Social Policy \& Administration, v. 42, n. 1, p. 43-58, Feb. 2008.

ORGANIZATION FOR ECONOMIC CO-OPERATION AND DEVELOPMENT (OECD). StatExtracts: Income distribution - Inequality. Disponível em: <http://stats.oecd.org/Index. aspx?DataSetCode=SOCX_AGG>. Acesso em: 6 maio 2012.

POLANYI, K. A Grande Transformação: As origens da nossa época. Tradução de Fanny Wrobel. 2. ed. Rio de Janeiro: Editora Campus, 2000.

RODRIK, D. Why do More Open Economies Have Bigger Governments? Journal of Political Economy, v. 106, n. 5, p. 997-1032, Oct. 1998.

TAYLOR-GOOBY, P. The Future of the British welfare state: public attitudes, citizenship and social policy under the Conservative governments of the 1980s. European Sociological Review, v. 4, n. 1, p. 1-19, May 1988.

TAVARES, M. C. Ajuste e reestruturação nos países centrais: a modernização conservadora. In: TAVARES, M. C.; FIORI, J. L. (Ed.). (Des)Ajuste Global e Modernizaçáo Conservadora. Rio de Janeiro: Paz e Terra, 1993. p. 21-73.

UNITED NATIONS. Department of Economic and Social Affairs, Population Division World Population Prospects: The 2010 Revision, CD-ROM Edition. 2011.

\section{The Centrality of Social Policy: an analysis of Thatcher Years}

\section{Abstract}

This article aims to show the impossibility of the neoliberal project to build an economy based on market forces. It also stresses the importance of social policies in the process of capitalism `s reproduction. From the analysis of the British experience in the period marked by the government of Prime Minister Margaret Thatcher, the paper intends to show how the attempts to create a market economy produced a social protection counter-movement. The latter can be noticed both in the increase of social expenditures as in the restructuring of social policies process.

Keywords: Economic crisis. Neoliberalism. Social policy. Social spending. 